\title{
Phytochemical screening and antimicrobial activity of roots, stem-bark and leave extracts of Grewia mollis
}

\author{
M. H. Shagal*, D. Kubmarawa and Z. Idi \\ Department of Chemistry, Modibbo Adama University of Technology, P.M.B. 2076, Yola, Adamawa State, Nigeria. \\ Accepted 9 March, 2012 \\ The roots, stem-bark and leaves of Grewia mollis which is used as herbal remedies for the cure of \\ diarrhea and dysentery by natives in northern part of Nigeria were studied. The ethanol and water \\ extracts of roots, stem-bark and leaves of the plant were subjected to phytochemical screening and \\ antimicrobial activity against Salmonella typhii, Escherichia coli, Streptococcus sp. and \\ Staphylococcus aureus. From the tests carried out, the result reveals the presence of saponins, \\ flavonoids, glycosides, tannins, volatile oils, alkaloids and phenols in the leaves extract of the plant. \\ The antimicrobial activity revealed that ethanol extracts of the plant parts were active against $E$. coli, $S$. \\ aureus and Streptococcus sp. This supports the claims of efficacy reported in fork use of the plant in \\ the treatment of disease caused by some pathogens and if further purified can be used as source of \\ novel antibiotics.
}

Key words: Grewia mollis, alkaloids, Escherichia coli, phytochemicals, cure.

\section{INTRODUCTION}

Nigeria is a varietal emporium of medicinal plants and is one of the richest countries in the world with regards to genetic resources of medicinal plants. It exhibits a wide range of topography and climate, which has a bearing on its vegetation and floristic composition. Moreover, the agro-climatic conditions are conducive for introducing and domesticating new exotic plant varieties.

Medicinal plants represent a rich source from which antimicrobial agents may be obtained. Plants are used medicinally in different countries and are a source of many powerful drugs (Srivastava et al., 1996). Herbal medicine represents one of the most important fields of traditional medicine all over the world. To promote the proper use of herbal medicine and to determine their potential as sources for new drugs, it is essential to study medicinal plants, which have folklore reputation in a more intensified way (Parekh, 2007).

In recent years, secondary plant metabolites (phytochemicals), previously with unknown pharmacological activities, have been extensively investigated as a source of medicinal agents (Krishnaraju et al., 2005). Thus, it is

*Corresponding author. E-mail: shagal2006@yahoo.com. Tel: 08052284456. anticipated that phytochemicals with adequate antibacterial efficacy will be used for the treatment of bacterial infections (Balandrin et al., 1985). Since time immemorial, man has used various parts of plants in the treatment and prevention of various ailments (Tanaka et al., 2002).

Contrary to the synthetic drugs, antimicrobials of plant origin have an enormous therapeutic potential to cure many infectious diseases as they can serve the purpose with lesser side effects. For example, vincristine (an antitumor drug), digitalis (a heart regulator) and ephedrine (a bronchodilator used to decrease respiratory congestion) were all originally discovered through research on plants. The potential for developing antimicrobials from higher plants appears rewarding as it will lead to the development of a phytomedicine to act against microbes (Iwu, et al 1999). Thousands of secondary plant products have been identified and it is estimated that thousands of these compounds still exist. Since secondary metabolic from natural resources have been elaborated within living systems, they are often perceived as showing more "drug likeness and biological friendliness than totally synthetic molecules" making them good candidates for further drug development. Biomolecules of plant origin appear to be one of the alternatives for the control of these antibiotic resistant 
human pathogens (Koehn, and Carter 2005; Balunas, 2005; Drahl, 2005).

The development of resistance to most of the available antimicrobial agents and the high costs of treatment consequent upon this resistance has necessitated a search for new, safe, efficient and effective agents for the management of infections. This research for new effective agents against infectious diseases and other diseases such as, cancers, diabetes, cardio-vascular, neurological, respiratory disorders, etc, has led to increased interest in existing information about the remedies of these diseases from natural sources, principally the plants (Simplice et al., 2011).

Grewia mollis, the plant of interest belongs to the family Tiliaceae. A savannah shrub or small tree present throughout the tropical region of the world, but mainly in South America, Africa and South East Asia, usually growing up to about 6 to $7 \mathrm{~m}$ and $30 \mathrm{~cm}$ girth, with bright yellow flowers. The plant has gum found in the inner stem-bark fiber and can be obtained by aqueous solvent extraction method. The gum is a solution in cold and hot water (Heywood et al., 2007)

The plant of study plays a major role in the production of local meals such as "Panke" (a cereal based fried product found mostly in the northern part of Nigeria). It is also used in the binding and polishing of "Daddawa' a fermented locust beans product rich in protein. The use of "Dargaza" in the production of these foods has helped in improving the acceptability of "Dargaza" product.

The aim of this work was to evaluate the antimicrobial potentials of this plant against some pathogenic bacteria and to determine the phytochemical constituents of the plant extracts which have been claimed to possess some ethno-medicinal uses.

\section{MATERIALS AND METHODS}

\section{Sampling and sample preparation}

Fresh sample of roots, stem-bark and leaves of the indigenous plant were collected from Biliri Local Government Area of Gombe State. The plant was identified with Voucher Number FD21113 by Dr. C. A. Amadi of Forestry Department, School of Agriculture and Agricultural Technology, Modibbo Adama University of Technology, P.M.B. 2076, Yola, Nigeria. The identified plant parts were washed with tap water and air-dried. The dried parts were chopped into pieces, milled into fine powder by pounding manually with a clean and sterile pestle and mortar. The powdered samples were each collected into sterile cellophane bags and labelled to prevent mix up. The samples were kept in cool dry place till further use. The powdered samples were used for extraction purposes.

\section{Extraction procedure}

$200 \mathrm{ml}$ of distilled water was added to $20 \mathrm{~g}$ each of the powdered samples in a flask. Each of the soaked sample was stirred, sealed with aluminium foil and allowed to stand for $72 \mathrm{~h}$. The content was then filtered with Whatman No. 1 filter paper. The filtrates were concentrated using rotary evaporator at $40^{\circ} \mathrm{C}$. The extracts were stored in a universal bottle and refrigerated at $4^{\circ} \mathrm{C}$ prior to use.
The same procedure was followed with another fresh sample as described above except that ethanol was used as solvent in the place of distilled water.

\section{Phytochemical screening}

Phytochemical screening for major constituents was undertaken using standard qualitative method as described by Odebiyi and Sofowora (1990) and Fadeyi et al. (1987). Alkaloids, tannins, flavonoids, phenols, glycosides, saponins and volatile oils tests were conducted in all the fractions. Results are shown in Table 1.

\section{Antimicrobial investigation}

Clinical isolates of Salmonella typhi (ST32011FMC), Escherichia coli (EC42011FMC), Staphylococcus aureus (SA52011FMC) and Streptococcus spp. (SS62011FMC) were obtained from the Microbiology Laboratory of Specialist Hospital, Yola, Adamawa State.

The stocks were maintained on nutrient agar slant and subcultured on nutrient broth for incubation at $37^{\circ} \mathrm{C}$ prior to each antimicrobial testing. Inoculation of the test organisms on nutrient agar prepared plates was achieved by flaming a wire loop on a spirit lamp, cooling the wire loop (air cooling) and fetching the test organisms. The discs were prepared using a Whatman filter paper and putting in vials-bottles and sterilizing in an oven at $150^{\circ} \mathrm{C}$ for 15 min. Prepared discs containing the various extracts were carefully placed on the inoculated plates using a sterilized forceps in each case (Fatope and Adoum, 1993). The plates were then turned upside-down and inoculated at $37^{\circ} \mathrm{C}$ for $24 \mathrm{~h}$ in an incubator. After incubation, the inoculated plates were observed for zones of inhibition (in mm diameter).

The result was taken by considering the zone of growth and inhibition of the organisms by the test fractions (Mackie and McCartney, 1989). Activity and inactivity were observed in accordance with the standard and acceptable method. Results are shown in Table 2.

\section{RESULTS AND DISCUSSION}

The results of phytochemical screening of ethanol and water extracts of leaves, stem-bark and roots of G. mollis are shown in Table 1. Saponins, taninins and phenols were found to be present in the ethanol extracts of leaves of the plant, while volatile oils, alkaloids, flavonoids and glycosides were absent. Tannins, volatile oils, phenols and glycosides were found to be present in the ethanol extracts of stem-bark of the plant, while saponins, alkaloids and flavonoids were absent. In the ethanol extracts of the roots, only tannins, volatile oils, falvonoids and phenols were present.

All the bioactive compounds tested in the water extracts of the leaves and stem-bark were present. However, in the roots extracts, only saponins and glycosides were absent.

Phytochemical screening of the extract varies from one plant part to another as shown in the results. It could also vary from place to place due to geographical location, climatic conditions and soil condition of a particular area. This may explain why it could be possible to have differences in chemical composition of the same plant 
Table 1. Results of the phytochemical screening of ethanol and water extracts of leaf, stem-bark and root of $G$. mollis.

\begin{tabular}{|c|c|c|c|c|c|c|}
\hline \multirow{2}{*}{$\begin{array}{l}\text { Bioactive } \\
\text { compound }\end{array}$} & \multicolumn{3}{|c|}{ Ethanol extract } & \multicolumn{3}{|c|}{ Water extract } \\
\hline & Leaf & Stem-bark & Root & Leaf & Stem-bark & Root \\
\hline Saponins & + & - & - & + & + & - \\
\hline Tannins & + & + & + & + & + & + \\
\hline Volatile oils & - & + & + & + & + & + \\
\hline Alkaloids & - & - & - & + & + & + \\
\hline Flavonoids & - & - & + & + & + & + \\
\hline Phenols & + & + & + & + & + & + \\
\hline Glycosides & - & + & - & + & + & - \\
\hline
\end{tabular}

$+=$ Present; - = absent.

Table 2. Results of antimicrobial activity of ethanol and water extracts of leaf, stem-bark and root of $G$. mollis. Diameter of zone of inhibition $(\mathrm{mm})$.

\begin{tabular}{lcccccccc}
\hline \multirow{2}{*}{ Test organism } & \multicolumn{3}{c}{ Ethanol extracts } & & \multicolumn{3}{c}{ Water extracts } & Gentamicin \\
\cline { 2 - 4 } & Leaf & Stem-bark & Root & & Leaf & Stem-bark & Root & (control) \\
\hline S. aureus & 22 & $\mathrm{R}$ & 24 & & 19 & $\mathrm{R}$ & $\mathrm{R}$ & 25 \\
Streptococcus spp. & $\mathrm{R}$ & 14 & 21 & & 7 & $\mathrm{R}$ & $\mathrm{R}$ & 25 \\
E. coli & 23 & 20 & 24 & & 18 & $\mathrm{R}$ & $\mathrm{R}$ & 26 \\
S. typhi & $\mathrm{R}$ & $\mathrm{R}$ & 19 & & $\mathrm{R}$ & 16 & $\mathrm{R}$ & 24 \\
\hline
\end{tabular}

$\mathrm{R}=$ Resistance.

of study in other areas.

Table 2 shows the antimicrobial activity of ethanol and water extract of the plant, in which the leaves of ethanol extract of the plant has antibacterial activities on the $S$. aureus and E. coli with the exception of Streptococcus spp. and S. typhi. The stem-bark of ethanol extract has antibacterial activities only on Streptococcus spp. and $E$. coli, while the other organisms were resistant. The ethanol extract of the roots showed activities on all the tested organisms. Water extracts showed that the leaves extract was active against $S$. aureus and $E$. coli. Also, the stem-bark extract was also active against $S$. typhi, while all other tested organisms were resistant against the water extracts of the stem-bark extract. The water extract of roots showed no activity on all the four tested organisms. Since the ethanol extract of the leaves and roots and the water extract of leaves inhibited the growth of $S$. aureus, then the plant could be employed in the treatment of some skin infections.

Diversity of medicinal plants and herbs containing various phytochemicals with biological activity can be of valuable therapeutic importance. Different phytochemicals have been found to have broad range of activities, which may help in protection against chronic diseases (Liu, 2003).

In practice, the plant of study, G. mollis was found by herbalist to be associated with the treatment of diarrhea in children. These suggest that the plant extracts could serve as a source of drugs for various chemotherapeutic purposes. The inhibition of the microorganisms: E. coli and Salmonella typhi has justified its uses for treatment against diarrhea and dysentery in the traditional medicine as reported by Kubmarawa (2007). The inhibitory activity of this extracts confirms its potential application in the treatment of microbial induced diseases.

In conclusion, the water extract of the roots, stem-bark and leaves of the plant possesses antimicrobial activities, and the use of the plant in ethno-medicine is thus authenticated.

Nigeria has some of the richest biodiversity plants of economic importance and plants of medicinal importance which when developed would reduce our expenditure on the imported drugs to meet our health needs. Therefore, I recommend that natural product chemist, botanist and microbiologist should be encouraged and be given financial support by the Government and private organizations. Government should also establish more research institutes for further research of traditional remedies as alternative medicine. I also recommend that further research on the studied plant should be done with other organic solvents that have higher polarity for complete and effective extraction of the soluble components of the plant parts. Further research is necessary to determine the antibacterial compounds present in these plants and also to determine their full spectrum of efficacy.

\section{REFERENCES}

Balunas MJ, Kinghorn AD (2005). Drug discovery from medicinal plants. Life Sci. 78: 431-441. 
Balandrin MF, Kjocke AJ, Wurtele E (1985). Natural plant chemicals: sources of industrial and mechanical materials. Science, 228: 11541160.

Drahl C, Cravatt BF, Sorensen EJ (2005). Protein-reactive natural products. Angew Chem. Int. Ed. Eng. 44: 5788-5809.

Fatope MO, Adoum OA (1993). "Bioactivity of some savannah plants in the brine shrimp lethality test and in-vitro anti-microbial assays, Int. J. Pharmacog. 35(5): 334-337.

Fadeyi MO, Adeoye AO, Olowokudejo ID (1987). Epidermal and phytochemical studies with genus of Bohervia (Nyctanginaceae) in Nigeria, Intl. J. Crude Drug Res. 27: 178-184.

Heywood ST, Brummit RK, Culham A, Seberg O (2007). Flowering plant. Families of the World. Firefly Books Richmond Hills, Ontario, Canada. ISBB. 1-55407-206-9.

Liu RH (2003). Health benefit of fruits and vegetable are from additive and cynergic combinations of phytochemicals, Am. A. Clin. Nutr. pp 517S-520S

Iwu MW, Duncan AR, Okunji CO (1999). New antimicrobials of plant origin. In: Janick J (ed.). Perspectives in New Crops and New Uses. ASHS Press, Alexandria, VA. pp. 457-462.

Koehn FE, Carter GT (2005). The evolving role of natural products in drug discovery, Nat. Rev. Drug Discov. 4: 206-220.

Kubmarawa D (2007). Preliminary phytochemical and antimicrobial screening of 50 medicinal plants from Nigeria, Afr. J. Biotechnol. 6(14): 1690-1696.

Krishnaraju AV, Rao TVN, Sundararaju D (2005). Assessment of bioactivity of Indian medicinal plants using Brine shrimp (Arternia salina) lethality assay, Int. J. Appl. Sci. Eng. 2: 125-134.
Mackie R, McCartney C (1989). Practical Medicinal Microbiology. $3^{\text {rd }}$ edition, Vol. 2 Churchill Livingstone publishers, London and New York. pp. 100- 106,121, 141, 163-167, 303, 432-491.

Odebiyi A, Sofowora AE (1990). Phytochemical screening of Nigerian Medicinal Plants. Part III. Lloyida. pp. 234-246.

Parekh J, Chaoda S (2007). In vitro antibacterial activity of the crude methanol extract of Woodfordia fruticosa kurz. Flower (lythraceae). Braz. J. Microbiol. 38: 204-207.

Simplice DK, Tchadjobo T, Denise PI, Jacques S (2011). Sub-Saharan Rubiaceae: A review of their Traditional Uses, Phytochemistry and Biological Activities, Pak. J. Biol. Sci. 14: 149-169.

Srivastava J, Lambert J, Vietmeyer N (1996). Medicinal plants: An expanding role in development, World Bank Technical. p. 320

Tanaka H, Sato M, Fujiwara S (2002). Antibacterial activity of isoflavonoids isolated from Erythrina variegata against methicillin resistant Staphylococcus aureus, Lett. Appl. Microbiol. 35: 494498. 